\title{
The Costs of Container Transport Flow Between Far East and Serbia Using Different Liner Shipping Services
}

\author{
Radoslav RAJKOVIC ${ }^{*}$, Nenad ZRNIC 2 , Đorđe STAKIC ${ }^{3}$ and Borut MAHNIC 4 \\ ${ }^{*}$ University of Belgrade, Faculty of Mechanical Engineering, Innovation center, Belgrade, Serbia \\ 2University of Belgrade, Faculty of Mechanical Engineering, Belgrade, Serbia \\ 3University of Belgrade, Faculty of Mathematics, Belgrade, Serbia \\ ${ }^{4}$ BOXLINE UCL d.o.o., Sežana, Slovenia
}

\begin{abstract}
Liner shipping is the most efficient mode of transport for goods. International liner shipping is a sophisticated network of regularly scheduled services that transports goods from anywhere in the world to anywhere in the world at low cost and with greater energy efficiency than any other form of international transportation. Liner shipping connects countries, markets, businesses and people, allowing them to buy and sell goods on a scale not previously possible. Today, the liner shipping industry transports goods representing approximately one-third of the total value of global trade. Ocean shipping contributes significantly to international stability and security. Considering the large and constant struggle in the market in terms of competitive pricing of products, a very important and indispensable role represents the container transport with a clear task to define the final price of the product. This paper analyzes the costs of container transport flow between Far East and Serbia, using different liner shipping services, observing the six world's largest container operators (Maersk Line, Mediterranean Shipping Company, CMA CGM, Evergreen Line, China Ocean Shipping Company and Hapag-Lloyd) and inland (truck-rail-river) transport corridors. These corridors include distance between selected Mediterranean ports (Koper, Rijeka, Bar, Thessaloniki, Constanta) and Serbia. As a result, in this paper is considered a mathematical model that provides a comparative analysis of transportation costs on the different routes. It is observed already existing transport routes and it is also given hypothetical review to the development of new transport routes. The main goal of this research is to provide an optimal route with lowest transportation cost during container transport. Selection of the best route in the intermodal network is a very difficult and complex task. The costs in all modes of transport and the quality of their services are not constant parameters and changes depending on a number of conditions and characteristics. The analysis of this model within combined maritime and land-based networks would prove helpful for the study of logistics chains, the hinterland-foreland continuum, intermodal transport systems, and market competitiveness.
\end{abstract}

Key words-Costs, Container transport, Liner shipping, Mathematical model.

\section{INTRODUCTION}

Liner shipping could lay claim to being the world's first truly global industry changing the shape of the world economy. Liner shipping networks are developed to meet the growing demand in global supply chains in terms of frequency, direct accessibility and transit times. It is the service of transporting goods by means of high-capacity, ocean-going ships that transit regular routes on fixed schedules. Liner ships transport approximately 60 percent of the value of seaborne trade or more than US $\$ 4$ trillion worth of goods annually. There are almost 500 liner shipping services providing regularly scheduled service (usually weekly) that enable goods to move between ports along the many trade routes of the world [1].

On the export side, liner trade is dominated by countries in East Asia. Liner exports are also highly concentrated, with the top ten exporting nations accounting for more than two-thirds of the total liner export value, and Greater China (including mainland China, Hong Kong S.A.R. and Taiwan, China) account for 28 percent of the value of liner exports and 30 percent of the global volume of containerized exports. On both the export and import side, European Union's liner trade is dominated by Germany, which accounts for 20 percent of EU liner exports and 17 percent of EU liner imports. The top four exporters and importers of the European Union (which include Germany, Italy, Netherlands, and the United Kingdom) also rank within the top 20 globally [1].

When designing their networks, shipping lines implicitly have to make a trade-off between the requirements of the customers and operational cost considerations. A higher demand for service segmentation adds to the growing complexity of the networks. Shippers demand direct services 
between their preferred ports of loading and discharge. Shipping lines may direct flows along paths that are optimal for the system, with the lowest cost for the entire network being achieved by indirect routing via hubs and the amalgamation of flows. The interaction between demand and supply on the trade route considered results in specific freight rate fluctuations and the overall earning potential on the trade. To achieve competitive price in the market as one of the important factors in the design of the final product price Importers try to reach the best possible transportation cost which is one of the most important problem in transport planning.

This paper analyzes the supply chain network with primary focus on import of containers from Far East to Serbia through selected Mediterranean ports (Koper, Rijeka, Bar, Thessaloniki and Constanta), observing the six world's largest container shipping lines (Maersk Line - MSK, Mediterranean Shipping Company - MSC, CMA CGM, Evergreen Line - EMC, China Ocean Shipping Company - COSCO and Hapag-Lloyd). Serbia is land-lock country and container import from Far East to Serbia needs to use different transport modes on inland to link shipping transport in the sea leg including railway, barge and truck.

In this study we developed optimization model, which minimize the transportation cost of container import from Far East to Serbia. The mathematical model was programmed in MATLAB and simulations were performed on an Intel Core i7-3612 QM 2.1 GHz computer. Through the minimization of transportation costs for container import from Far East through Mediterranean nodes it was determined the most optimal route for container import to Serbia which reached a number of 42000 TEU in 2012.

The findings presented will help managers and companies to improve their business performance by following constant market changes and making reliable comparisons.

The rest of this paper is organized as follows: Section 2 describes the problem which is considered in this work while the mathematical model is explained in Section 3. Section 4 reports and analyses the results of the mathematical model. Finally, Section 5 is devoted to conclusions and future development.

\section{LITERATURE REVIEW}

Although literature on freight transportation is large, containers assignment on intermodal networks is still an open issue. Studying literature data we conclude that a small number of researchers investigated at the same time see and land legs together $[2,3,4]$. In most cases it is developed an optimization model which is based on the minimization for just one objective transportation cost $[5,6,7,8]$.

Similar research in terms of testing the bi-objective optimization minimizing cost and transit time conducted Lam, J. S. L. and GU, Y. [2] observing import and export container flow to and from inland China. The results and analysis offer managerial insights of the impact of trade-offs between cost and transit time, and the effect of different carbon footprint requirements on transport planning. Yang, X., Low, J. M. W. and Tang, L. C. [3] presents an intermodal network optimization model to examine the competitiveness of 36 alternative routings for freight moving from China to and beyond Indian Ocean. The proposed model is able to handle multiple and conflicting objective functions such as minimizing transportation cost, transit time and transit time variability while ensuring flow continuity and transit nodes compatibility among the rail, road, ocean vessel, airplane and inland waterway transports. In the Min [4] article are developed a chanceconstrained goal programming model to aid the distribution manager in choosing the most effective intermodal mix that not only minimizes cost and risk, but also satisfies various on-time service requirements.

The papers with main objective of minimizing the sum of shipping and inland transportation costs are presented by authors H. J. Kima, Y. T. Changa, P. T. W. Leeb, S. H. Shina and M. J. Kima [5]. They solved the problem by mixed integer programming, which is an operations research technique. A case study is performed on the container cargo data in Korea and they draw several implications to improve efficiency in the transportation of international trade cargoes in Korea. The focus of D. Infante, G. Paletta and F. Vocaturo [6] are on intermodal freight transport service in which containers represent the moved loading units, minimizing the total cost of the service. They formulated a ship-truck intermodal transportation problem as a Travelling Purchaser Problem (TPP). Computational results indicate that theirs algorithm is very efficient on a set of benchmark instances, quickly achieving optimal or near-optimal solutions. Very similar study was conducted by D. C. Francesetti [7] who analyzed the costs of shipping containers from four Chinese ports to representative central European destinations. It is demonstrated that the sum of costs by sea and 
costs over land, using both truck and rail transport, clearly favours the Italian ports, above all those of Genoa and Trieste for a geographic range that does not include all the Northern countries of the European Union and Russia but does cover a considerable portion of the southernmost cities of these countries such as Milan, Munich, Vienna, Budapest, Bern, Lyon, and Kiev. The purpose of his paper was to define costs in each sector (shipping costs, port costs and inland distribution costs) and to compare the relative port positions. M. M. Han, L. Guolong and Y. Bin [8] considered the problem of determining transportation quantity and mode in transporting international cargoes between Myanmar and her trading countries, especially focusing on the countries in South East Asia to check the extent of using short sea shipping, and inland transportation. The objective of theirs paper is to minimize transportation costs by mode between cargo origin and destination, subject to the maximum cargo volumes being handled at each seaport, in order to optimize the short sea shipping and inland transportation in Myanmar.

\section{Problem Formulation}

Intermodal transportation network, based on the import-way are composed by two legs. The first one represents ocean transfers from loading port - Shanghai port to Mediterranean ports (Koper, Rijeka, Bar, Thessaloniki, Constanta). Inland component of the distribution as second leg of the intermodal chain represents the transport way in which containers are routed from selected ports to final destination - Belgrade, by road, rail or barge.

The network is composed by three categories of nodes: origin port (port of loading), gateway ports (ports of discharge) and destination (place of delivery), and two categories of links, maritime and inland.

\section{A. Nodes}

Origin port - As one of the most important foreign trade partners in container imports from the Far East to Serbia is China with major port - port of Shanghai. It is the world's busiest trading port which handles a staggering 32 million containers a year, carrying 736 million tons of goods to far-flung places around the globe.

Gateway ports are connected with origin port, but only by incoming links. From origin port it is possible to reach a gateway port but the opposite is not allowed since here we are addressing only incoming flows. The main gateways for container import to Serbia are Koper, Rijeka, Bar, Thessaloniki and Constanta port.

Destination - Serbia is land-lock country with capital city - Belgrade. This region represents the largest percentage of Serbian imports in general. It is connected to the gateway ports with a direct link, representing the shortest path to reach it from that gateway, by road, rail and barge.

\section{B. Links}

On the maritime leg we considered six different container shipping lines (top six) with theirs different type of services on the west-bound route networks from Shanghai to gateway ports in Mediterranean. Today, there are 5,954 ships active on liner trades, for 18,022,997 TEU and 228,921,278 TDW Including 4,967 fully cellular ships for 17,549,308 TEU. The rank list of first 20 largest operators is illustrated in Fig. 1. 


\begin{tabular}{|r|l|r|r|r|r|r|r|r|r|r|r|}
\hline \multicolumn{2}{|c|}{} & \multicolumn{2}{|c|}{ TOTAL } & \multicolumn{2}{c|}{ Owned } & \multicolumn{3}{c|}{ Chartered } & \multicolumn{3}{|c|}{ Orderbook } \\
\hline Rnk & Operator & \multicolumn{1}{|c|}{ TEU } & Ships & TEU & Ships & TEU & Ships & $\%$ Chart & TEU & Ships & $\%$ existing \\
\hline 1 & APM-Maersk & $2,656,709$ & 569 & $1,483,655$ & 249 & $1,173,054$ & 320 & $44.2 \%$ & 256,710 & 15 & $9.7 \%$ \\
\hline 2 & Mediterranean Shg Co & $2,426,655$ & 487 & $1,038,181$ & 189 & $1,388,474$ & 298 & $57.2 \%$ & 438,851 & 38 & $18.1 \%$ \\
\hline 3 & CMA CGM Group & $1,520,630$ & 429 & 526,288 & 83 & 994,342 & 346 & $65.4 \%$ & 373,957 & 37 & $24.6 \%$ \\
\hline 4 & Evergreen Line & 875,242 & 198 & 509,479 & 108 & 365,763 & 90 & $41.8 \%$ & 290,800 & 24 & $33.2 \%$ \\
\hline 5 & COSCO Container L. & 756,291 & 153 & 400,667 & 93 & 355,624 & 60 & $47.0 \%$ & 87,158 & 8 & $11.5 \%$ \\
\hline 6 & Hapag-Lloyd & 750,696 & 153 & 407,439 & 65 & 343,257 & 88 & $45.7 \%$ & 13,169 & 1 & $1.8 \%$ \\
\hline 7 & APL & 628,722 & 117 & 363,343 & 48 & 265,379 & 69 & $42.2 \%$ & 23,200 & 2 & $3.7 \%$ \\
\hline 8 & CSCL & 603,646 & 133 & 432,283 & 73 & 171,363 & 60 & $28.4 \%$ & 155,216 & 11 & $25.7 \%$ \\
\hline 9 & Hanjin Shipping & 602,990 & 104 & 284,846 & 40 & 318,144 & 64 & $52.8 \%$ & 100,720 & 11 & $16.7 \%$ \\
\hline 10 & MOL & 599,175 & 117 & 216,972 & 35 & 382,203 & 82 & $63.8 \%$ & 100,000 & 10 & $16.7 \%$ \\
\hline 11 & Hamburg Süd Group & 492,384 & 109 & 253,165 & 43 & 239,219 & 66 & $48.6 \%$ & 104,784 & 12 & $21.3 \%$ \\
\hline 12 & NYK Line & 475,417 & 106 & 300,513 & 54 & 174,904 & 52 & $36.8 \%$ & 112,000 & 8 & $23.6 \%$ \\
\hline 13 & OOCL & 475,091 & 88 & 333,336 & 48 & 141,755 & 40 & $29.8 \%$ & 48,760 & 5 & $10.3 \%$ \\
\hline 14 & Yang Ming Marine Tran & 388,965 & 87 & 224,326 & 46 & 164,639 & 41 & $42.3 \%$ & 233,380 & 20 & $60.0 \%$ \\
\hline 15 & PIL (Pacific Int. Line) & 358,503 & 165 & 248,916 & 114 & 109,587 & 51 & $30.6 \%$ & 46,800 & 12 & $13.1 \%$ \\
\hline 16 & Hyundai M.M. & 358,169 & 59 & 125,510 & 19 & 232,659 & 40 & $65.0 \%$ & 99,300 & 9 & $27.7 \%$ \\
\hline 17 & K Line & 350,562 & 67 & 127,352 & 21 & 223,210 & 46 & $63.7 \%$ & 69,350 & 5 & $19.8 \%$ \\
\hline 18 & Zim & 323,403 & 83 & 133,394 & 25 & 190,009 & 58 & $58.8 \%$ & & & \\
\hline 19 & UASC & 275,834 & 49 & 198,164 & 26 & 77,670 & 23 & $28.2 \%$ & 281,926 & 19 & $102.2 \%$ \\
\hline 20 & CSAV Group & 248,002 & 50 & 80,889 & 15 & 167,113 & 35 & $67.4 \%$ & 65,100 & 7 & $26.2 \%$ \\
\hline
\end{tabular}

Figure 1 - Rank list of operators (source: Alphaliner)

The inland legs include different modes of transport (truck, rail and barge) from selected ports to the final destination. From each of the ports is not possible to perform all types of transport. Their interconnection is shown in Table 1.

Table 1. Modes of transport from discharge ports to final destination

\begin{tabular}{|c|c|c|c|}
\hline $\begin{array}{c}\text { Ports / Modes of } \\
\text { transport }\end{array}$ & Truck & Rail & Barge \\
\hline Koper & $\mathrm{x}$ & $\mathrm{x}$ \\
\hline Rijeka & $\mathrm{x}$ & $\mathrm{x}$ \\
\hline Bar & $\mathrm{x}$ & $\mathrm{x}$ \\
\hline Thessaloniki & $\mathrm{x}$ & $\mathrm{x}$ & \\
\hline Constanta & $\mathrm{x}$ & & \\
\hline $\mathrm{x}-$ connection with Belgrade & & \\
\hline
\end{tabular}

iV. Mathematical MOdel

The main goal of this mathematical model is to minimize the sum of shipping and inland transportation costs for three different types of containers. The transport cost was considered for each of the most commonly used types of containers in the container transport, and is based on the Free On Board - FOB term. Total cost includes, except the cost of transport from Shanghai to Belgrade, local costs in the port of discharge, customs clearance and handling costs. During inland transport it was used different modes of transport, and because of more appropriate comparisons of the costs of rail and barge with truck, it was included also handling costs at the terminal in Belgrade and final delivery to users by truck (local delivery).

Finally, in this model it was given a rank list and possibility to sort and make a list of the best possible solutions regarding minimization of transportation costs for the each type of container.

For each of three types of containers can be independently count minimum price of transport. Besides, the implementation in MATLAB can make the whole ranking list price for each type of container in particular.

This section presents the model formulation and corresponding explanations are given as follows:

$\mathrm{N}$ - set of nodes, let $N=S \cup E \cup B$, while $S$ stands for origin port, E stands for gateway ports stands for place of delivery

A - set of arcs connecting an origin to a gateway (first-leg arcs)

C - set of arcs connecting gateways to place of delivery (second-leg arcs) 


\section{Parameters:}

$n_{i}$ - number of operators

$n_{j}$ - number of ports

$n_{k}$ - mode of transports

CSE $E_{i j}$ - transportation cost on first-leg arcs (expressed in \$)

EX - exchange rate $(€ / \$)$

CPC $C_{i j}$ - port cost (expressed in $€$ )

$C E B_{j k}$ - transportation cost on second-leg arcs (expressed in $€$ )

Decision variables:

$t_{i j}$ - binary cost variable representing containers flow on first-leg arc, operator " I " to gateway " $\mathrm{j}$ ", where, $t_{i j} \in\{0,1\}$

$\mathrm{l}_{\mathrm{jk}}$ - binary cost variable representing containers flow on second-leg arc, gateway " $\mathrm{j}$ ", mode of transport "k", $l_{j k} \in\{0,1\}$

where $i \in\left\{1, \ldots, n_{i}\right\}, j \in\left\{1, \ldots, n_{j}\right\}, k \in\left\{1, \ldots, n_{k}\right\}$. In our case study we use input arguments $n_{i}=6, n_{j}=5, n_{k}=3$.

Objective function:

Minimize Cost $=$

$$
\sum_{(i, j) \in A}\left(C S E_{\mathrm{ij}} \frac{1}{E X}+C P C_{i j}\right) * t_{i j}+\sum_{(j, k) \in C} C E B_{j k} * l_{k j}
$$

Constraints:

$$
\begin{aligned}
& \sum_{(i, j) \in A} t_{\mathrm{ij}}=1 \\
& \sum_{(j, k) \in C} l_{\mathrm{jk}}=1 \\
& \sum_{(\mathrm{i}, \mathrm{j}) \in \mathrm{A}} \mathrm{t}_{\mathrm{ij}}=\sum_{(\mathrm{j}, \mathrm{k}) \in \mathrm{C}} \mathrm{l}_{\mathrm{jk}}, \forall \mathrm{j}
\end{aligned}
$$

Corresponding Explanations:

The objective function (1) minimizes total cost of container import flow through the transport network. They include transport cost on the first leg-arc (ocean costs), port cost and transport cost on the second leg-arc (cost of using inland vehicles - truck, rail and barge. Constraints (2) and (3) define a single best solution for cost from a group of ordered pairs on the maritime and inland part. Constraint (4) selects the same port for the first and second leg-arc and defines one route from origin to place of delivery regarding transportation cost.

\section{RESULTS AND ANALYSIS}

Mathematical model which minimize transportation costs of container import from Shanghai to Belgrade is developed. Optimization model was programmed in MATLAB and simulations were performed on an Intel Core i7-3612 QM 2.1 GHz computer. We use original input data regarding first half of 2013. The results are presented through two different scenarios which are described below:

Scenario 1: In this scenario we analyze one objective optimization ("Min cost") where the optimal transportation cost between Shanghai and Belgrade per each container (20 Dry Van - DV, 40 Dry Van - DV, 40 High Cube - HQ) are respectively $1594 €, 2470 €, 2483 €$ using see and land legs together. These data are valid for the period August 2010. Since container transport on Danube (barge transport) from Belgrade to Constanta is not currently active, these data can be regarded 
only as hypothetical. The first valid data regarding minimum price for transport between Shanghai and Belgrade base on FOB term per each type of container are given in Table 2. For all type of containers the minimum transport cost are reached using operator MSC on the maritime leg and using rail on the land leg.

Scenario 2: In this scenario we discussed one objective optimization ("Rank list by cost"). Observing the results we spotted that the cost for 20 DV ranged between $1594 €-3219 € 40$ DV between $2470 €-4230 €$ and $40 \mathrm{HQ}$ between $2483 €-4297 €$. These results are presented total transportation cost per each type of container and sorted by ascending order to provide us credible information about their exact place in the ranking list on the transportation route between Shanghai and Belgrade. The rank list is starting point for the introduction of the new objective into the model which should be subject of future studies as the two most common considerations in transport planning problems.

Table 2. Optimal transportation cost per containers

\begin{tabular}{l|l}
\hline Port of loading & Shanghai \\
\hline Operator & MSC \\
No.of transshipments & 1 \\
Service & DRAGON / WEST MEDITERRANEAN \\
Route & Shanghai - Yantian - Hong Kong - Chiwan - Singapore - Gioia Tauro / Gioia \\
& Tauro - Rijeka \\
Port of discharge & Rijeka \\
Mode of transport & Rail \\
Place of delivery & Belgrade \\
Optimal rate 20 DV & $1639 €$ \\
Optimal rate $40 \mathrm{DV}$ & $2550 €$ \\
Optimal rate $40 \mathrm{HQ}$ & $2587 €$ \\
\hline
\end{tabular}

\section{CONCLUSION}

The linear shipping sector is one of the most dynamic sectors of ocean transport, and one that is also inextricably connected to the port and terminal sector and to land transport modes due to its intermodal nature. A crucial development during last twenty years is the increasing degree of containerization which makes shipping and handling of cargo far more efficient.

This paper analyzes the supply chain network with primary focus on import of containers from Shanghai to Belgrade through selected Mediterranean ports, observing the six world's largest container operators (Maersk Line, Mediterranean Shipping Company, CMA CGM, Evergreen Line, China Ocean Shipping Company and Hapag-Lloyd) with theirs different type of services. Serbia is land-lock country and container import from Far East to Serbia needs to use different transport modes on inland to link shipping transport in the sea leg including railway, barge and truck. The main goal of this research is to provide an optimal route with lowest transportation cost of different type of container import from Shanghai to Belgrade.

Mathematical model give us possibility to get reliable data of the minimal cost on the observed route per each type of container. The advantage of this model is that it gives us the possibility of observation beside of the optimal price, also the group of all possible solutions, which are ranked in ascending particular order and its applicability to various "point to point" relations, in which containers are transported by combination of sea and land. In accordance with developed mathematical model and the corresponding objective function as the main contribution of the paper is set aside adequate applicability in practical logistical flow of goods.

Computational results shows us that the lowest transportation costs between Shanghai and Belgrade, per each type of containers are reached using MSC operator on the maritime leg and rail transport on the land leg. 
Further research is needed, because this research is recited only part of the problem. It can be extended in the future and can be imported with a lot of new nodes and new objectives such as transit time and emissions.

\section{ACKNOWLEDGMENT}

The study was carried out within the Project TP - 36027, "Software development and national database for strategic management of the development of means of transport and infrastructure in road, rail, air and water transport by European transport network models", financed by the Ministry of Education Science and Technological Development, Republic of Serbia.

\section{REFERENCES}

1. Review of Maritime Transport: UNCTAD/RMT/2014. United National Publication Sales no. E. 13.II.D.9, ISBN 97892-1-112872-7, e-ISBN 978-92-1-054195-4, ISSN 0566-7682. Available from Internet: <http://www. vi.unctad.org/digital-library/?task=dl_doc\&doc_name...reviewma

2. J. S. L. Lam and Y. Gu., "Port hinterland intermodal container flow optimisation with green concerns: a literature review and research agenda," International Journal of Shipping and Transport Logistics (IJSTL), vol. 5, issue 3, pp. 257-281, January 2013.

3. X. Yang., J. M. W. Low and L. C. Tang, "Analysis of Intermodal Freight from China to Indian Ocean: A Goal Programming Approach," Journal of Transport Geography, vol. 19, issue 4, pp. 515-527, 2011.

4. H. Min, "International intermodal choices via chance-constrained goal programming," Transportation Research Part A: General, vol. 25, issue 6, pp. 351-362, November 1991.

5. H. J. Kima, Y. T. Changa, P. T. W. Leeb, S. H. Shina and M. J. Kima, "Optimizing the transportation of international container cargoes in Korea," Maritime Policy \& Management: The flagship journal of international shipping and port research, vol. 35, issue 1, pp. 103-122, 2008.

6. D. Infante, G. Paletta and F. Vocaturo, "A ship-truck intermodal transportation problem," Maritime Economics \& Logistics, vol. 11, pp. 247-259, September 2009.

7. D. C. Francesetti, "Italian versus Northern Range port competitiveness: a transportation cost analysis in Chinese trade," European Transport \Trasporti Europei, vol. 30, pp. 37-53, 2005.

8. M. M. Han, L. Guolong and Y. Bin, "A Linear Programming Model For Short Sea Shipping And Multimodal Inland Transportation In Myanmar," Report and Opinion, vol. 3, issue 1, pp. 37-43, 2011.

\section{AUTHORS}

R. Rajkovic is with the University of Belgrade, Faculty of Mechanical Engineering, Innovation center, Kraljice Marije 16, 11000 Belgrade, Serbia (e-mail: rrajkovic@mas.bg.ac.rs).

N. Zrnic is with the University of Belgrade, Faculty of Mechanical Engineering, Kraljice Marije 16, 11000 Belgrade, Serbia (e-mail: nzrnic@mas.bg.ac.rs).

Đ. Stakic is with the University of Belgrade, Faculty of Mathematics, Studentski trg 16, 11000 Belgrade, Serbia (e-mail: djordjes@gmail.com).

B. Mahnic is with the BOXLINE UCL d.o.0., Partizanska cesta 97, 6210 Sežana, Slovenia (e-mail: bobymahnic@gmail.com). 